\title{
A Story of CBAE for Future Art Educators
}

\author{
Susan Whiteland, Arkansas State University \\ $\underline{\text { swhiteland@astate.edu }}$
}

\begin{abstract}
A community-minded university professor tells the story of five students who were involved in an independent-studies course that involved painting a large wall mural at a behavioral health center. The experiential learning in studio core content was combined with curriculum appropriate for future art educators that included art criticism, recognition of diversity, contemporary art themes, and civic involvement. Through problem solving, collaboration, and learning from one another, the students gained valuable knowledge that they felt could help them in their future art classrooms. Their reflections suggest that community art education has something to offer curriculum for future art educators.
\end{abstract}

Key Words: Community-Based Art Education; Mural; Curriculum

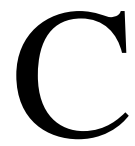

ommunity-based Art Education (CBAE) is specific to a particular locale, focused on the needs of individuals, potentially empowering them to support personal artistic endeavors, and facilitating social change. Most often CBAE is also positioned outside of a K-12 school setting (Ulbricht, 2005). Similar in concept is place-based education (PBE). The phrase refers to learning that is concerned with the history, environment, culture, economy, literature and art of a particular place (Jennings, Swidler \& Koleba, 2005). In this article the terms CBAE and PBE are interchanged when referring to the community as context and community members as resources and partners.

Considering that the main focus of my university's BFA Art Education degree is to prepare licensed art teachers for the public school system, it may seem counter-productive to implement a curriculum focus that is outside that system. So, why implement CBAE as part of the curriculum for future art educators? As a reflective practitioner responsible for curriculum development and coordinating the art education program in my fine arts college, I investigated the question, acting as a participant observer in a case study with five undergraduate art education students who were involved in a community-based art education experience. This article shares our story.

Literature Review

The literature suggests several advantages for including community-based education within the framework of university curricula. Teacher preparation courses in art and other fields report using community-based instruction to enhance students' understanding of core content (Gruenwald, 2003; Jennings, Swidler \& Koliba, 2005); as an experiential learning mode (Berg, 2012; Brown, 2011; Duncum, 1999; Smith, 2002); as a method to acknowledge diversity (Ball \& Lai, 2006; Clark \& Zimmerman, 2000; Congdon, 2005; Kumashiro, 2000); as an avenue to relate learning to contemporary themes (Jeandron \& Robinson, 2010; Miele \& Powell, 2010; Taylor, 2002); and as a method to instill civic mindedness (O'Hara, 2001; Stokamer, 2013). Lim, Chang, \& Song (2013) conducted a study of pre-service art educators who were involved in community art projects. The researchers found that the university students involved in CBAE developed 
professional characteristics and found relevancy in curriculum as it pertained to student needs and real life. The pre-service art educators grew in their ability to work personally and collaboratively. They learned how to advocate for the arts. They expanded their teaching content and made connections to community. Lawton (2010) advocates community-based art activities as a means to promote art making and learn within a real-world setting. Sang (2009) advocates community-based models of art education to strengthen relationships between schools and public or private organizations. Freedman (2011) writes that effective art education involves connecting the visual arts to a variety of societal aims as well as educational goals. Russell and Hurtzel (2007) say including community members in collaboration on art projects serves the needs and interests of the public and seeks change in society beyond aesthetic responses to artwork. Washington (2011), on a similar note, says community-based art education transforms learning spaces into settings where art can relate to the problems of life and not just exist for the sake of art itself. Some of these same themes surfaced in the reflections of my students during our mural production at a local behavioral health facility.

Community Connection: Behavioral Center

It was at the beginning of the fall semester when I placed a telephone call to the director of nursing at a community facility that serves as a behavioral treatment center for our city of 70,000 residents. The person on the other end of the phone had emailed the art department's Chair to see if the department could recommend a student who might be interested in doing a little painting at the center. The nursing director wanted to give some of the walls a new look, adding color to what she described as oatmeal. I thanked her for thinking of our university and promised that I would visit her in the next few days. I had recently completed a mural in another city at a seniors' recreation facility and thought that a mural project for my students might be a worthwhile experience to involve them in community outreach and practice their painting skills. I asked one of the painting instructors if she would be interested in promoting the project with some of her students.

My role at the university is to coordinate the art education emphasis and assist art students who are interested in teaching to obtain their licensure requirements. Perhaps the email from our departmental secretary had been forwarded to me because she was aware of my desire for art education students to have community involvement. Part of my rationale is practical in that I want them to be aware of the ubiquitous nature of art education. It is all around them and I want them to recognize that if they decide to leave their intended career path of teaching in the public school system, they have other options in the community. Smith (2002) suggests that students who are engaged in placed-based curriculum such as that encountered in communitybased art education discover future economic opportunities as they become aware of community jobs.

During the next week following my telephone conversation with the nursing director I visited the behavioral facility. I was greeted warmly by the receptionist and then was led through several secured doors to meet with the nursing director. As we talked I learned that the director enjoyed trompe l'oeil paintings that fool the eye. She originally had in mind an art student painting signs that would embrace encouragement to those who were in treatment. As we visited she began to re-conceptualize the painting project and dreamed of having a wall mural that would be a source of inspiration for the patients. One of the stops during our tour was the activity pavilion where patients could enjoy Ping-Pong, arts and crafts and games. The director pointed out a wall about 25 ' long and asked my opinion about the kind of wall painting that my students 
might be able to do there. I took several pictures and told her that I would like to set up a meeting with her, the studio professor and myself to discuss themes and procedures that we might use.

I followed up with the nursing director in an email the next day. I attached an example of the mural that I had been involved with in another location. I asked her to survey clients and staff at the behavioral center to determine their interest in participating in the project, either in the planning stages, procuring images for consideration, or in the painting process. I also wanted input from the staff and patients to determine what they would like to see incorporated in the mural. The nursing director assured me that she would conduct a survey and advise me of what she found out. In the meantime, three university students had expressed interest in the mural project and were eager to put ideas together for a design.

Within the next week the nursing director emailed me with results from her survey. The staff said,

"Make it look like downtown"

"Any activities that people would do"

"Bright pictures that are uplifting, colorful and positive"

"The positive words and or sayings that are uplifting like the word hope embedded in images that are pleasant". (J. C., personal communication, August 27, 2013)

The Director added that the staff would like to be involved. In the survey of the patients they answered the question about participating with an overwhelming "Yes". The patients said that they would like to see animals, outdoor scenes, water running like rivers or waterfalls, people living their lives and local scenes or games that they play in the unit. (J. C., personal communication, August 27, 2013)

I thanked the nursing director for her survey responses in a reply email and clarified what I needed from her as a project coordinator. I recommended that she be responsible for securing paint and supplies, and obtaining approval for the wall design and placement. I asked that she supply the release forms necessary for the university students to work with the patients. We also set a date for a planning meeting among the studio painting professor, the nursing director, the activity director, and myself at the behavioral facility. At that time we would look at any photos and drawings that had been collected for consideration of inclusion in the mural.

During the planning meeting I showed the nursing director several of the photos that the university students had taken that related to the local environment. They included wooded scenes, waterfalls, and animals from the local habitat. She excitedly picked out a number of the photos that she felt would fulfill what the patients at the center had requested. We discussed developing a landscape motif for the mural that would be refreshing and somewhat nostalgic. The landscape would not be figurative in any way for fear of making the patients uncomfortable. We determined that the mural should include recognizable landmarks and fauna associated with local community and the general vicinity of North East and Central Arkansas. A deadline was set for the university students to develop a rough draft of the mural for the director's approval.

Planning the Design

Duncum (1999) recommends art educators integrate professional and personal lives by acknowledging an enjoyment of everyday aesthetic sites. The university art students who were designing the behavioral center mural were unknowingly following Duncum's advice. They sifted through photographs that they had taken on family outings and walks in the park. They reveled in the delicate beauty of wildflowers, and reflecting brilliance of cascading waterfalls. They made line sketches of the photographs drafting their idea for the mural. In the problem 
solving process they employed their understanding of design to create continuity and points of interest.

Gruenwald (2003) writes that place-based education does not dismiss the importance of content and skills. He says the study of place can increase student's engagement and understanding, offering learning that is multidisciplinary. The university students learned to negotiate and collaborate as they planned and sketched out components of the mural. They also shared anecdotal stories of personally visiting the sites that they were incorporating into the mural design.

Taylor (2002) describes a postmodern work of art as one that involves collaboration and viewer participation. He says cultural identity expressed in mini-narratives connect art and life, employing critical self-reflection and transformation. Postmodern artists evaluate how and why they make art. The art students exemplified this trend. They were involved in frequent conversations determining what imagery should be used and the messages it might convey to the viewers at the behavioral center.

The university students met the rough draft deadline and I emailed it to the nursing director for approval. We scheduled work times when the students could come to the center to begin gridding the wall in order to transfer the design. The goal was to have a pencil rendering of the mural on the wall before the Thanksgiving holidays. I shared in the process of preparing the wall as well as painting the mural. Brown (2011) would say that the students and I developed a sense of community based on a shared object. I took on the role of active participant alongside the students. We developed mutual trust in each other's capability to contribute to the shared learning that was taking place.

See Figure 1.

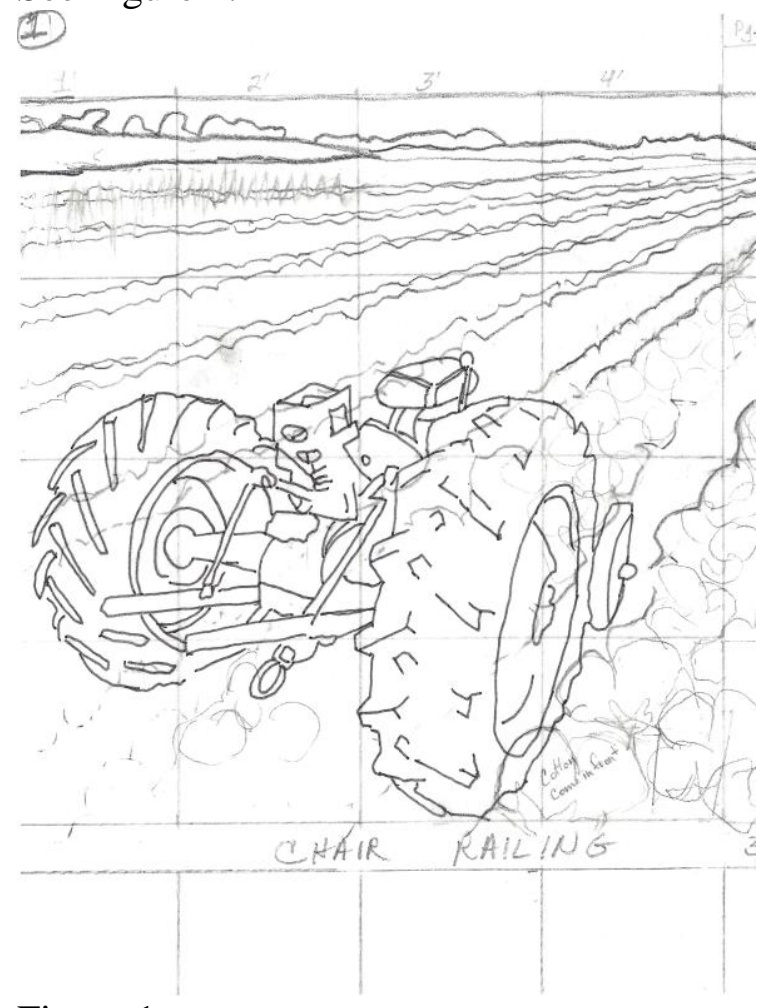

Figure 1

Gridded Line Drawing of Tractor for Wall Transfer 
Immediately prior to the beginning of the spring semester I emailed the nursing director to check times when the students could come to work at the behavioral facility. I found that the nursing director was no longer affiliated with the treatment center. She had passed her mural coordinator responsibility to the activity director. Changes had also occurred with the students who were committed to working on the mural. One of the original three elected to spend more time on his personal artwork. However, three other students had decided to join our efforts. As added incentive for the students I was able to offer our mural project as an independent study course worth three hours of studio credit under the auspices of the painting instructor. This was a bonus for several of the students. The painting professor and I based the grading criteria for the course on active participation and a written reflection to be submitted as a final document at the conclusion of the project. Three of the university students were classified as art education majors and one student was a non-traditional painting and drawing student who was toying with the idea of becoming an art educator.

It seemed fitting to me to promote the mural project as not only an exercise in painting techniques but also a teaching occasion for the art education students to work with others who were not academically trained in art. I anticipated that we could have both staff from the behavioral center and patients working with us during the painting stage of the mural's production. Clark and Zimmerman (2000) report that in traditional school settings rural artists or those perceived as different are often undervalued. We had only three patients and two staff members from the behavioral center join our efforts. Nevertheless, I observed the university students positively interacting with the community members who could be considered as different. Kumashiro (2000) says that place-based curriculum helps students to learn about diversity without stereotypical biases. Assumptions and prejudices were disrupted regarding what the university students may have previously believed about patients and medical staff in a behavioral treatment center.

Painting Begins

A typical day of working on the mural consisted of the students and I meeting in the lobby of the behavioral center at about 1:00 in the afternoon. We signed in a visitor's log and placed in lockers any objects of value. We were then escorted by one of the interns at the facility past three series of locked doors and down a long hallway leading to the recreation room or activity pavilion where the mural was located. On our way to the mural we would often observe adults of varying ages and ethnicities sock-footed and dressed in scrub-type uniforms conversing with one another. We also passed a nursing station where several nurses would be on duty charting medical records. After passing the final set of locked doors we gathered our painting supplies and ladders that were kept under lock and key in an annex room. The facility provided quarts of latex paint in the primary colors, plus black and white. Some of the other colors that we used were from our own stockpile of acrylic paints. We often spent a brief time critiquing the previous day's work and setting goals for what we each hoped to accomplish during the twohour painting session. We logged in the time that we arrived, turned on the radio and began to paint while observed from an adjacent room by our escort.

Smith (2002) says what happens in a classroom experience is typically mediated by the teacher. This was not the case as we engaged in mural painting at the behavioral center. It was bodily experienced, tied to the needs of others, collaboratively analyzed, reflected upon and valued. Taylor (2002) recalls Dewey's theory of experience as contributing to true education as it involves observation, knowledge and judgment. In our mural painting experience I as the teacher 
was not the holder of knowledge. Knowledge was constructed through the interactions and experiences of us all as mural painters.

As the days progressed and we began to reach the end of the semester and of the mural project I had several people share with me their enthusiasm for the mural. A custodian of the facility commented that the mural was an encouragement to the patients. A local newspaper correspondent visited the site while we were working and reported on how the mural was adding positivity to the surroundings. The correspondent was prompted to comment on elements of the mural, remembering her own experiences that took place at the locales represented. Listening to the stories of the reporter brought meaning to what Jennings, Swidler and Koliba (2005) say about place-based education - that it is rooted in unique, history and environment, providing a rich context for learning.

The studio professor provided a critique for the mural as we neared the final days of work. Minor adjustments were suggested and most were acted upon. Autonomy was given to each of the muralists as they worked on specific sections to which they felt ownership. Collaboration, cooperation, negotiating results and conflict resolution were characteristics that the students exhibited as they worked with each other. Jennings, Swidler and Koliba (2005) say that community-based learning builds camaraderie that fosters care and value among members. Despite differences in experience levels, ages, and backgrounds we valued each other's contributions and decision-making (see figures 2 and 3 ).

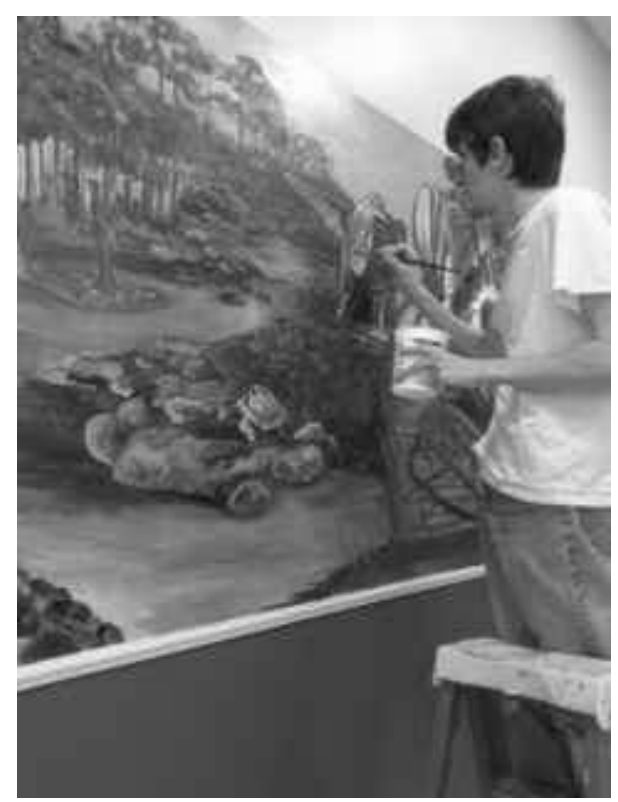

Figure 2

University student paints landscape created from photos of regional fauna. 


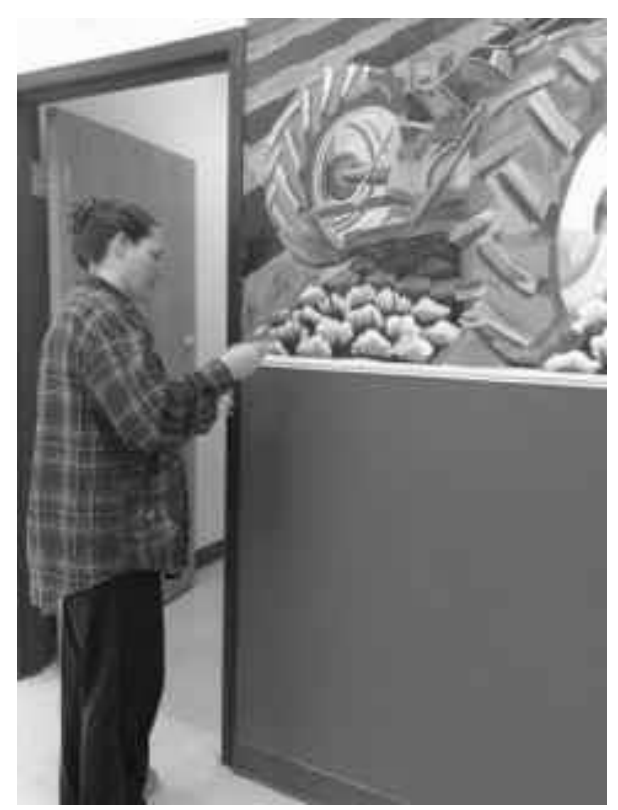

Figure 3

University student paints landscape typical of rural farming community.

\section{Reflections}

Brown (2011) utilizes a reflection model known as DEAL to help his students review and evaluate experiential learning such as what takes place during community-based art education. The model includes three components: (1) description of an experience, (2) analysis of the experience based on a personal, civic and academic level, and (3) articulation of learning outcomes. Bowen says with the DEAL model students are encouraged to push beyond superficial interpretations. The university students who were enrolled in the mural painting class were asked to respond to five reflective prompts that were modified versions of the DEAL model. The prompts I gave the students enrolled in the mural painting class were as follows:

1. Identify and describe an art technique, process, or concept that you now understand better as a result of your work on the mural.

2. Compare and contrast what you previously knew about an art technique, process or concept to what you have now learned from working on the mural.

3. In what ways do you feel like your experience at the Behavioral Health Center has impacted you as an artist, student or community member?

4. What effects or benefits do you believe the mural has had or will have in the future for others who have participated in its creation or who have viewed the work and/or its progress?

5. What could you or the mural organizers have done differently during the mural making process and what characteristics of the experience do you hope to replicate in the future?

It is informative to consider the papers that the students submitted in response to the prompts. One student had very little experience with painting prior to the project. In her reflection she acknowledges the skills that she acquired as a result of learning by experience in a real-world situation. Her reflection on the class gives testimony to the benefits she believed she received from CBAE in the area of skill development. She wrote the following: 
As a result of working on the mural at the Behavioral Health Center, I have learned some of the basic concepts of painting...I better understand how to blend different colors to get the right desired color. In the mural class I had to mix for colors that had many different hues and values along with colors that were beyond the tertiary quadrant. I also learned more on how to give and take criticism and apply it appropriately to my work.

(A. S., personal communication, May 5, 2014)

Her statement echoes Lawton's (2010) promotion of artmaking in a real world setting. While these comments might also have been written by a student taking a traditional studio class, her response on the additional benefits she believed that she gained were unique to the community-based art experience and influential for her future career goal of becoming an art teacher. She wrote, "I hope to be able to do community projects like this with my classrooms." (A. S., personal communication, May 5, 2014)

Another student commented on the technical skills he acquired through the communitybased art education experience as well as his learned collaboration with fellow artists. He said, This project has given me valuable painting experience. Before I had limited experience with both painting large scale and with acrylics. The concept was daunting and I was unsure of how well I would succeed. This has helped me improve in both facets. Because of the large scale of the painting teamwork was a necessity. We all worked as a group by dividing the mural into sections based on our individual skills and interests. As we worked on our own sections we also teamed up with constructive criticism for ways to improve each other's sections and improve the whole.

(T. R., personal communication, May 2, 2014)

When reflecting on the community aspect of the project the student shared his newfound understanding of his local environment and civic mindedness that he developed through the process. He wrote:

Despite how close the Behavioral Clinic was to both the campus and where I live, I knew little about it. I have learned some things about the place and the people who both work and reside there. While working on the mural, what made it most worthwhile was how excited both the employees and residents were to see it progress to completion. I am glad to have gotten to participate in something that will bring joy to people who might need it. I hope to get to continue to participate in similar projects to improve my community. This project has shown me how my skills can be used to improve others' lives and I hope to be able to do so. The only thing I feel we should have changed is better use of painters tape to preserve the area around the mural. I also wish more residents could have participated in working on the mural to help promote the community aspect of its implementation. I feel all of this information would be valuable for me as a future art teacher. Through this I have learned technical skill, teamwork, and the value of public service.

(T. R., personal communication, May 2, 2014)

The student's reflection on the mural project relates well with Taylor's description of a postmodern view of art. Taylor (2002) says, "Postmodern art may be considered a transformative vehicle of sorts in that the process of and participation in its creation and interpretation may serve to transform both the artist and viewer." (p. 125)

Another student expressed in her reflective paper that she grew in more ways than she expected. She felt that the community art experience benefitted her as an artist, team member and as a future teacher. She wrote: 
When asked to work on the mural, I was thinking it would be a new experience for me to work on something bigger with other artists while having some influence in my community. I must say it has put much more knowledge than expected in my hands and I am sure I will be able to implement (the knowledge) in the things I work on in the future. I have always liked to teach and while working on the mural, I have been reminded of this once more. For me, a fun part of doing the mural is helping some of the other artists learn how to mix paint and get the effects of color transition. I love to see people grow in their understanding and I feel I saw a lot of this during the project. The teamwork has been very beneficial for all involved because we have encouraged and learned from each other. I think it is something that would be good for every art student to experience.

(P. P., personal communication, April 30, 2014)

Themes that ran through the students' reflections in favor of CBAE included improvement of art skills, working collaboratively as a team, self-satisfaction and civicmindedness. Although the mural project took place in an off-campus community setting, opportunities for interaction with clients at the behavioral health center or staff members were minimal. This limited the social reconstruction in our project, which is often a result of CBAE. Staff at the center scheduled our work on the mural when clients were not present in the recreational area. This policy may have been for safety of the university students or for the privacy of the clients in the facility. Only three clients and two staffers took advantage of working with our mural team, although the students did have the opportunity to collaborate with the project director at the facility. The clients who painted seemed to take part as a type of reward for positive behavior and personal interests. Other negatives of the experience that became apparent to me were minimal. They included time restrictions where the students were only allowed to work during convenient times for the community partner, the mixed ability levels of the participants working on the mural required additional time for team members to work through problem areas, and limited art supplies encouraged team members to supply their own resources.

The students' positive reflections on what they learned from CBAE involvement outweighed the time constraints and supply needs. The students' words signify value in having community-based art education as part of the curriculum for pre-service art educators. It was through CBAE that the students learned art techniques and processes in an authentic situation where it mattered. Beyond improving their painting skills the students learned valuable lessons in setting priorities, meeting deadlines, working with others, negotiation and conflict resolution. Through the community service aspect of the project the students developed sensitivity and empathy with community members whom they had previously not noticed.

When the last day of working on the mural arrived I made a tally of the number of hours that were put in on the production. From the time that the wall was gridded to the finishing touch of paint that was applied, 208 hours were logged. There were a total of five students, two staffers, three patients and myself who had a hand in the mural's creation. Looking at one of Lim, Chang and Song's (2013) questions that queries what kinds of benefits pre-service art teachers achieve through community involvement and outreach, I find we met several objectives with our project. The mural provided a method for future art educators to link theory with practice (Ulbricht, 2005). This took place in the design and actual painting of the piece as university students improved art skills and peer taught. Diversity was explored as the artists learned to listen and collaborate with each other. Each member of the team, including the clients and employees of the center who participated, brought their own experiences and skills to the 
project. The professionals and staff who were employed by the center shared that they enjoyed watching the mural's process and saw it as a reflection of serenity and refreshment. This suggests that the mural improved the lives of those who resided at the center, characterizing Freedman's (2011) rationale for connecting visual art with societal aims. Those who read the newspaper story about the community-based art mural became aware of a strengthened relationship between the university and the public/private organization such as Sang (2009) advocates.

Overall, the experiential learning in studio core content was combined with curriculum appropriate for future art educators that included art criticism, recognition of diversity, contemporary art themes, and civic involvement. Through problem solving, collaboration, practicing art skills in an authentic environment, and learning from one another as well as from previously unrecognized community members, the students gained valuable knowledge that they felt could help them in their future art classrooms. Their reflections suggest community-based art education has something to offer curriculum for future art educators (see figures 4 and 5).

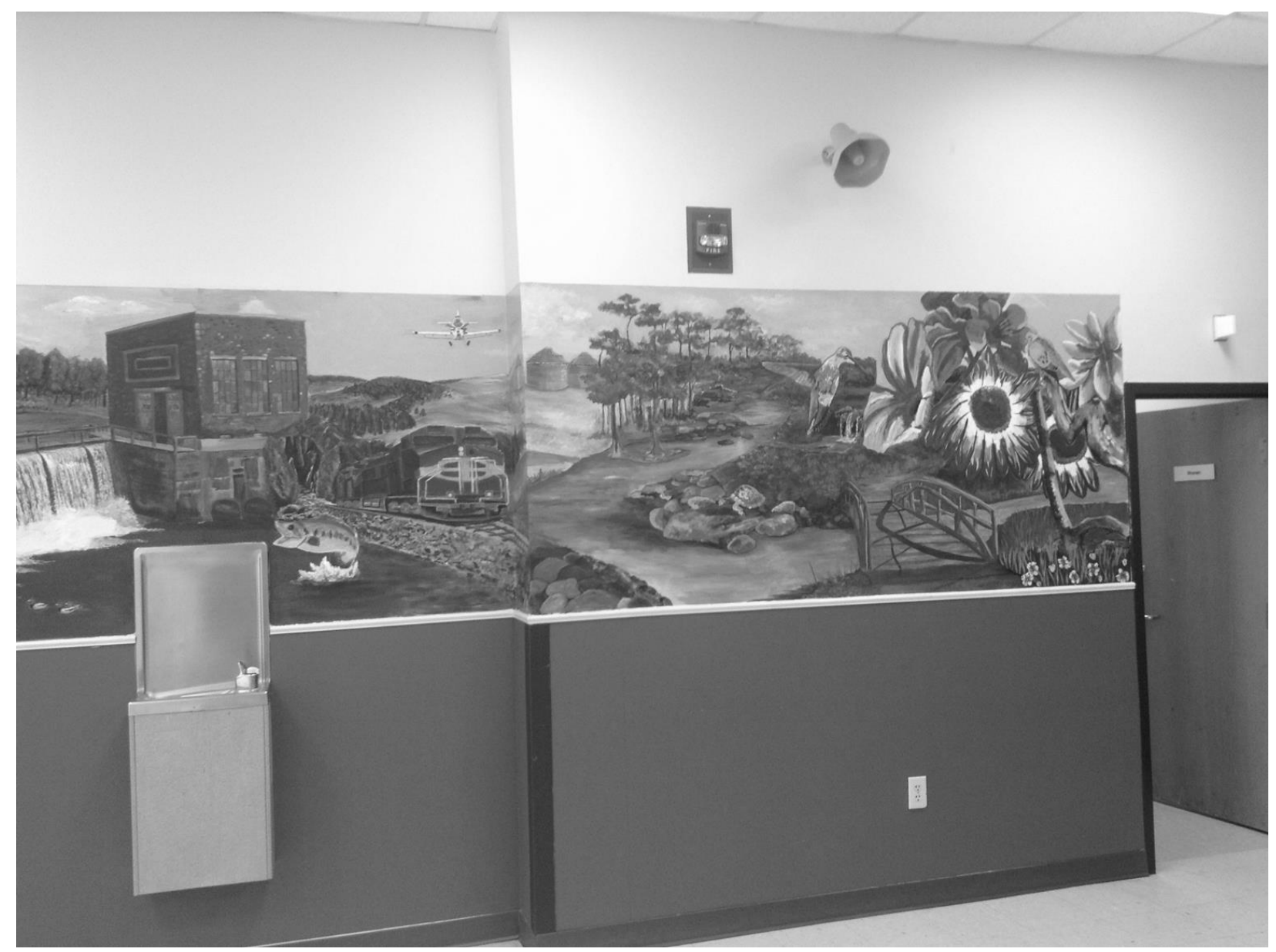

Figure 4

Center and right side of mural including local landmarks. 


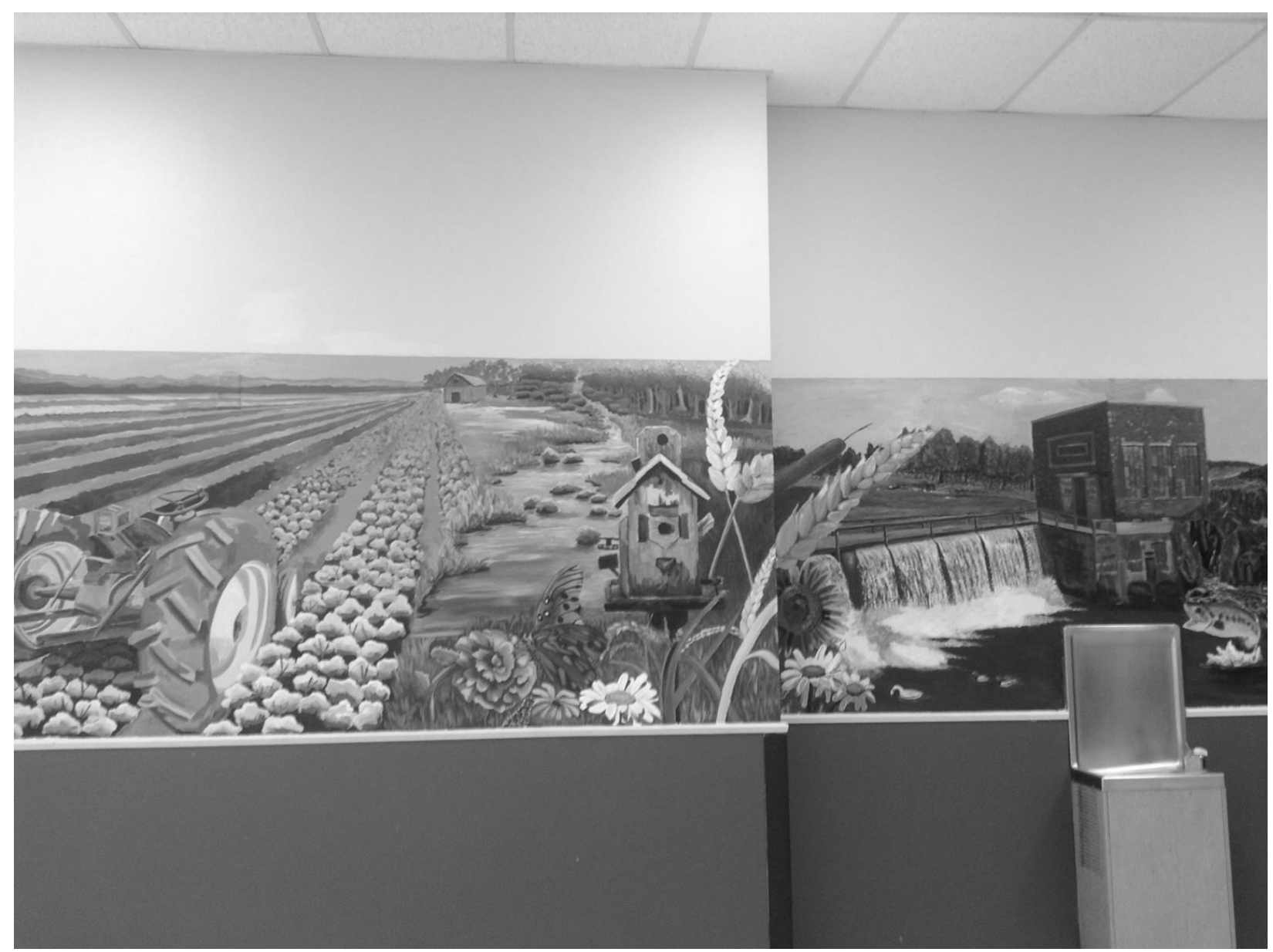

Figure 5

Left side of mural illustrating local landscape.

\section{References}

Ball, L. B., \& Lai, A. (2006). Place-based pedagogy for the arts and humanities. Pedagogy, 6(2), 261-287.

Berg, J. (2012). What's "best" in our practices? Currents in Teaching and Learning 4(2), 53-55.

Brown, K. (2011). A pedagogy of blending theory with community-based research. International Journal of Teaching and Learning in Higher Education, 23(1), 119-127.

Clark, G. \& Zimmerman, E. (2000). Greater understanding of the local community: A community-based art education program for rural schools, Art Education, 53(2), 33-39.

Congdon, K. G. (2005). What I have learned from "Other" art educators. Studies in Art Education, 46(2) 138-149. 
Duncum, P. (1999). A case for art education of everyday aesthetic experience. Studies in Art Education, 40(4) 295-311.

Freedman, K. (2011). Leadership in art education: Taking action in school and communities. Art Education, 64(2), 40-45.

Gruenewald, D. A. (2003). The best of both worlds: A critical pedagogy of place. Educational Researcher, 32(4) 3-12.

Jeandron, C, \& Robinson, G. (2010). Creating a climate for service learning success. American Association of Community Colleges (NJI). Retrieved from http://www.aacc.nche.edu/Resources/aaccprograms/horizons/Documents/creatingaclimate_0820 10.pdf

Jennings, N., Swidler, S., Koliba, C. (2005). Place-based education in the standards-based reform era-conflict or complement? American Journal of Education, 112, 44-65.

Kumashiro, K., (2000). Toward a theory of anti-oppressive education. Review of Educational Research, 70 (1) 25-53.

Lawton, P. (2010). Hand-in hand, building community on common ground. Art Education, 63(6), 6-12.

Lim, M., Chang, E., \& Song, B. (2013). Three initiatives for community-based art education practices. Art Education, 66(4), 7-13.

Miele, E. \& Powell, G. (2010). Cultural and natural resources at the core of a place-based, science teacher preparation program. Journal of College Science Teaching, 40(2), 40-44.

O'Hara, L. (2001). Service-learning: Students' transformative journey from communication student to civic-minded professional. Southern Communication Journal 66(3), 251-266.

Russell, R., \& Hutzel, K. (2007). Promoting social and emotional learning through servicelearning art projects. Art Education, 60(3), 6-11.

Sang, A. (2009). International Journal of Education Through Art $5(2+3)$ Success through collaboration: A community-based model for pre-service teachers, 187-200.

Smith, G. (2002). Place-based education: Learning to be where we are. Phi Delta Kappan, 83(8) 583-594.

Stokamer, S. (2013). Pedagogical catalysts of civic competence: The development of a critical epistemological model for community-based learning. Journal of Higher Education Outreach and Engagement 17(1), 113-121. 
Taylor, P. (2002), Service-learning as postmodern art and pedagogy. Studies in Art Education, 43(2), 124-140.

Ulbricht, J. (2005). What is community-based art education? Art Education, 58(2) 6-12.

Washington, G. (2011). Community-Based Art Education and Performance: Pointing to a place called home. Studies in Art Education 52(4), 263-277. 